\title{
La imagen proyectada por la Bética costera durante los siglos II a.c. a I d.c: un análisis iconológico de su acuñación monetal
}

\author{
The image projected by the coastal Baetica during \\ the IInd century $B C$ to the Ist $A D$ : an analysis from \\ the monetary iconology
}

\author{
ELENA MoRENO PULIDO* \\ Universidad de Cádiz
}

\section{RESUMEN}

Este trabajo tiene como objetivo el estudio de la iconografía monetaria de las cecas marítimas de la Bética, desde los inicios de su acuñación hasta el cierre de las mismas. El análisis sincrónico, iconográfico e iconológico conjunto de su

numerario muestra las conexiones económicas y culturales entre estas ciudades, a la vez que presenta visualmente el avance de la romanización, así como la integración de estas comunidades, tradicionalmente púnicas, en la cultura latina.

\section{PALABRAS CLAVE}

Arqueología, Bética, Iconografía, Iconología, Imagen, Numismática.

\begin{abstract}
This work takes as a target the study of the monetary iconography of the marine mints of the Baetica, from the beginnings of his coinage up to the closing of the same ones. The synchronous iconographic and iconologic analysis of his money shows the economic and cultural connections between these cities, simultaneously it presents visually the advance of the roman civilization, as well as the integration of these communities, phoenician traditionally, in the Latin culture.
\end{abstract}

\section{KEYWORDS}

Archeology, Baetica, Iconography, Image, Numismatic.

* Universidad de Cádiz. Dirección postal: Jesús Nazareno, 19 5수 11002, Cádiz. Correo electrónico: elena.moreno@uca.es 


\section{INTRODUCCIÓN*}

El intento de descubrir a través de la Arqueología los aspectos ideológicos de las sociedades de la Antigüedad resulta, aún hoy, una tarea muy ardua. Sin embargo, a la hora de acercarnos al estudio de las mentalidades y los aspectos «blandos» de la cultura, las representaciones iconográficas monetarias resultan de gran ayuda. La moneda es una de las fuentes de información histórica más significativas puesto que, a pesar de lo reducido de su tamaño, ofrece imágenes, leyendas, cronologías... en suma, datos valiosísimos para la interpretación del pasado. Los tipos representados fueron (y son) cuidadosamente escogidos por el Estado, ya que el numerario es uno de los principales vehículos de expresión y de propaganda oficial del poder. Gracias a su capacidad de llegar a cualquier persona o lugar, la moneda se convierte en reflejo veraz de la sociedad que la emitió y en crónica de la época en la que vivió. Las representaciones contenidas en ella nos dan una enorme información que va desde imágenes religiosas a históricas o legendarias, pasando, por supuesto, por las económicas, a menudo relacionadas con fases económicas premonetales.

El objetivo de esta exposición es tratar de analizar en conjunto las imágenes que aparecen en la Bética costera, desde la aparición de la moneda local hasta el cierre de las cecas, a través del estudio pormenorizado, iconográfico e iconológico, de las tipologías monetarias de las ciudades acuñadoras. Se pretende seguir la evolución, de forma sincrónica, de las imágenes que se eligieron como emblemas de cada ciudad, para intentar descubrir cómo ocurre el cambio cultural desde la propia esencia de cada ciudad (fenicio-púnica en su mayoría, por tratarse del Sur Peninsular) hacia la integración plena en el sistema iconográfico romano y, por tanto, en el sistema ideológico cultural y político del Imperio Romano.

El presente trabajo pretende, pues, descubrir cómo se produce el cambio de mentalidad e ideología, en definitiva, cómo se engendra la asimilación cultural de unos pueblos con idiosincrasia propia en la supuesta homogeneidad que deseaba el Imperio Romano. Para ello, a través de las tipologías monetarias, los programas iconográficos se estudiarán en conjunto y buscando las relaciones que convierten, poco a poco, las cecas béticas en una misma unidad cultural que proyecta una imagen determinada de sí misma con la que quiere ser relacionada en todo el Mediterráneo.

Para la consecución de estos objetivos se estudiarán, desde los inicios de su acuñación, todas las cecas que emitieron moneda en la costa Sur peninsular de la Ulterior-Bética. Este criterio geográfico responde al planteamiento que presupone

* Este estudio se inserta en el proyecto de tesis Tradición local e integración en el Imperio Romano del Círculo del Estrecho y su periferia: Un análisis monetario desde la Iconografía, dentro del Programa de Doctorado con Mención de Calidad de la Universidad de Cádiz (DCT2004-00382), Fretrum Gaditanum: Sociedades Históricas gaditanas en el marco del Círculo del Estrecho y del Mediterráneo. De la Prehistoria al Medievo, dirigido por la Profa. Dra. Alicia Arévalo, a quien agradezco profundamente sus continuos ánimos y su desinteresado apoyo. Asimismo, se integra dentro de las líneas del grupo de investigación HUM-440 del IV PAI de la Junta de Andalucía. 
una respuesta iconográfica similar a la fuerte influencia del mar, que impregna la vida cotidiana de las ciudades litorales y se refleja en aspectos tan significativos como sus recursos, deidades y comercio. Las cecas que se tratarán en este trabajo son, por orden alfabético: Abderat (Adra, Almería); Aipora (cerca de Sanlúcar de Barrameda, Cádiz); Baesippo (entre Vejer y Barbate, Cádiz); Bailo (Bolonia, Cádiz); Carteia (Cortijo del Rocadillo, San Roque, Cádiz); Gadir (Cádiz); Iulia Traducta (Algeciras, Cádiz); Malaca (Málaga); Onuba (Huelva) y Seks (Almuñécar, Granada) (Fig. 1).

La elaboración de un análisis sincrónico y pormenorizado de la iconografía de las cecas de la Ulterior-Bética costera necesita la reflexión en forma de síntesis sobre la idea global que las imágenes representadas en las monedas muestran de la realidad política, económica y religiosa del momento. Esta síntesis pretende plantear la generalidad tipológica mostrada por el litoral bético y busca comprender cómo los procesos que llamamos «romanizadores» afectaron a la ideología de las ciudades costeras de la Bética, transformándolas y adaptándolas a la cultura itálica a través de las imágenes grabadas en las monedas.

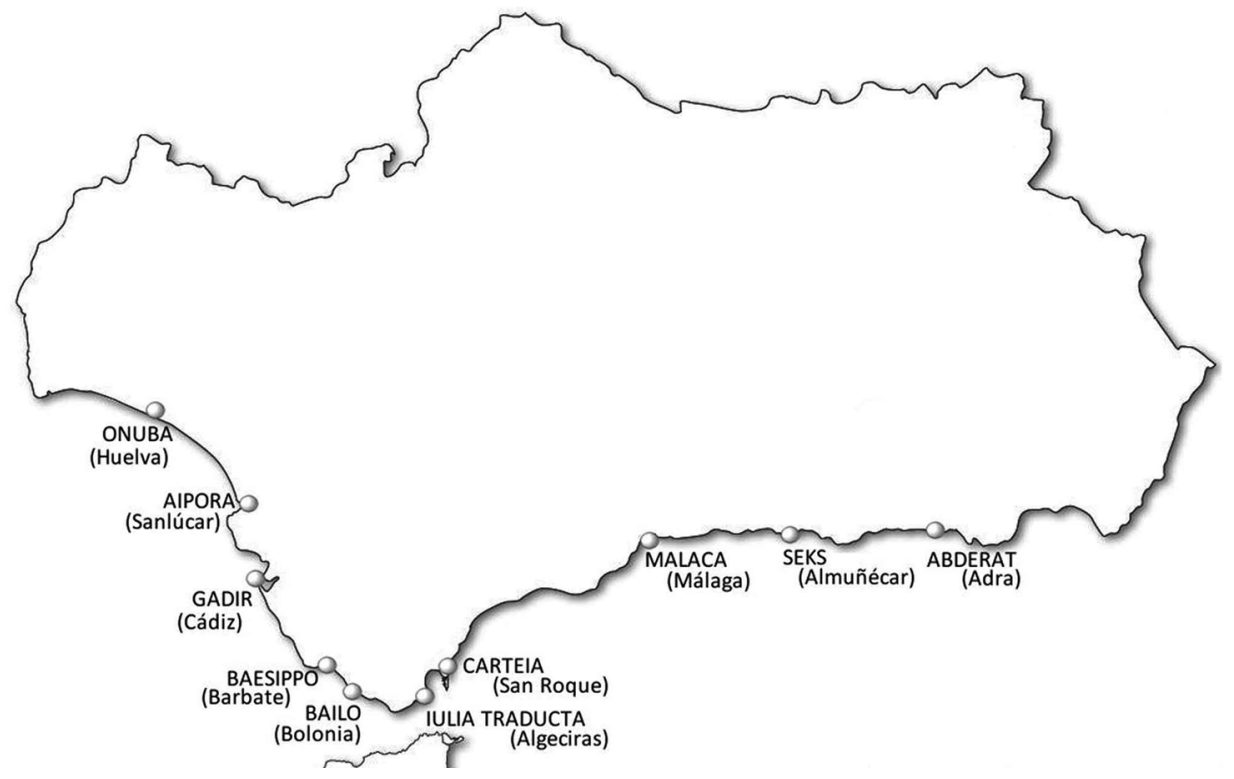

Fig. 1. Mapa de las cecas costeras de la Bética.

\section{LAS PRIMERAS ACUÑACIONES: EL SIGLO III a.C.}

Las primeras emisiones de la Bética Costera datan del siglo III a.C. y muestran una elección tipológica basada en unos criterios que responden a necesidades particulares de cada ciudad. (Tabla 1). 


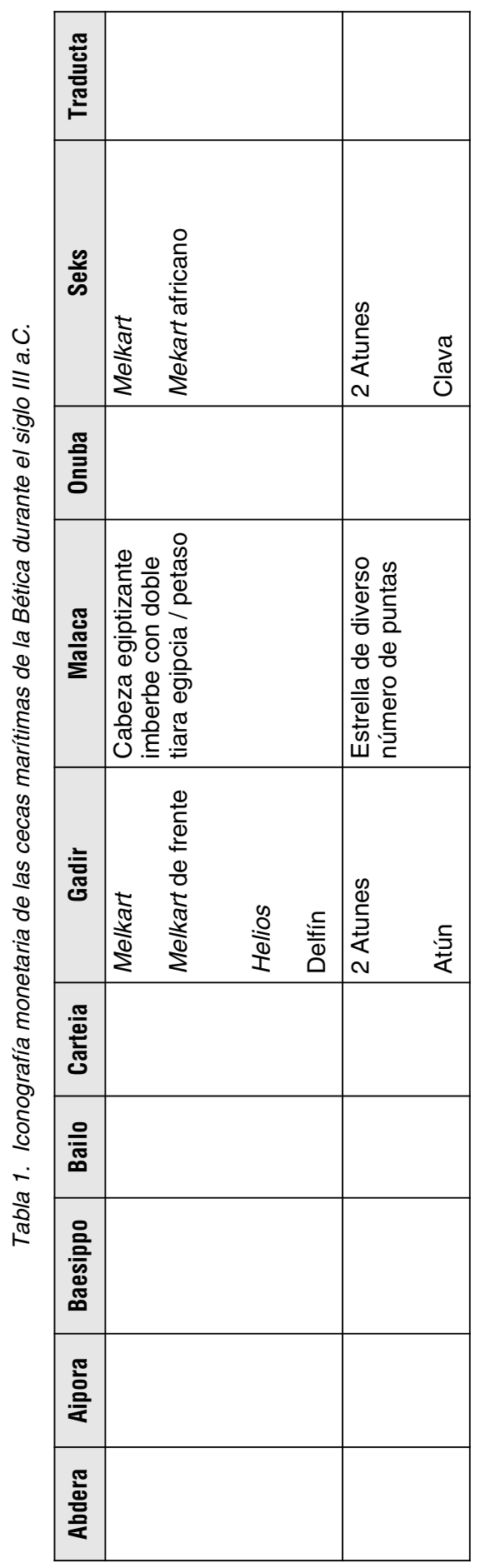


A principios del siglo III a.C., Ebussus (Ibiza) y Gadir se introducen en la economía monetaria. Ambas ciudades poseían, desde antiguo, importantes puertos comerciales, lo cual había favorecido el conocimiento de moneda foránea en sus territorios. La finalidad de las acuñaciones iniciales de Ebussus (CNH 91.1-2, 92.3-11) y Gadir (CNH 82.1-84.34) se vincula con las primeras actividades cartaginesas en Iberia, que utilizaron estas dos ciudades como bases aliadas y como puentes entre Carthago y la Península Ibérica. La temprana implantación de la economía monetaria en estas dos ciudades ha de ponerse en relación con el deseo de facilitar las transacciones locales, ya que no circularían en principio más allá de su ámbito local (Alfaro 1979, 1997 y 2004; Campo 1976 y 1993).

Exceptuando el sugestivo caso de la ceca de Gadir, el resto de colonias fenicias hispanas no comenzarán su acuñación hasta bien iniciada la II Guerra Púnica; estas ciudades serían las cecas púnicas de Malaca (CNH 100.1-8), Seks (CNH 103.1 y 104.2-4) o Baria (Villaricos, Almería) (CNH 74.87 y 89). Emitirán sólo monedas de bronce ${ }^{1}$, de poco valor financiero, lo cual revela el hecho de que la moneda en estos momentos nunca se usó para grandes pagos comerciales o estatales a gran escala, no se intentaba en modo alguno monetizar la economía, al contrario, el numerario se utilizó de manera esporádica para cubrir determinadas necesidades oficiales.

Tras el interludio que supuso la dominación cartaginesa de la Península, ésta volverá a ser un mosaico de pequeñas ciudades de diferente adjudicación cultural, cuya iconografía en general encarna las divinidades patronas y los productos por ellas amparados, utilizando la moneda como medio de prestigio y de independencia frente a Roma.

Dentro de la koiné mediterránea y helenística donde estaba sumida, Gadir escoge desde un primer momento el tipo que la representará durante toda su acuñación, Melkart-Herakles tocado con leonté y con un estilo fuertemente influido por las tendencias helenísticas de este período (CNH 82.1, 83.2-9, 84.10$13,84.18-19,85.20-21,85.30-34)$. Tal y como acuñaría una ciudad-estado griega, Gadir escoge para su anverso la divinidad fundadora, tutelar y patrona más importante para el Occidente Mediterráneo. Para su reverso, alude a la principal riqueza de la ciudad, producto a su vez amparado por la divinidad: el atún. El templo oracular de Melkart-Herakles se presenta como una entidad que controla la vida económica de la ciudad y así lo demuestra al monopolizar con la imagen del dios la acuñación gaditana. Se trata por tanto de una emisión basada en los cánones helenísticos y en los estereotipos creados desde la aparición de la moneda en Grecia.

Seks va a unirse a las emisiones monetarias peninsulares bien entrado el siglo III a.C. y lo hará siguiendo los esquemas iconográficos planteados por Gadir. Sin duda va a copiar la amonedación que esta ciudad llevaba emitiendo desde décadas atrás. Va a presentar una imagen del dios Melkart-Herakles basada en el es-

1 Gadir y Malaca acuñarán, de manera esporádica, plata de poco valor y en pequeñas cantidades. Estas breves emisiones argénteas se han puesto en relación con el inmediato contexto bélico. 
quema gaditano, con leonté en anverso y con dos atunes en reverso, deseando participar del prestigio que tenían las monedas que la vieja ciudad de Gadir emitía. Esta reputación era fundamental para la confianza que la moneda debía suscitar en sus usuarios, una mayor confianza en el numerario originaría una mayor seguridad en las transacciones comerciales para las que, en última instancia, se crearía esa moneda y que se traduciría en un mayor ámbito de circulación de la misma, así como en abundantes ganancias para la ciudad. De este modo, Seks, desde un primer momento, se beneficia de las ideas que desprendía la imagen de MelkartHerakles en las mentalidades mercantiles, tanto populares como aristocráticas, mediterráneas. La imagen de esta divinidad tenía suficiente fuerza y era sobradamente comprendida por todo el público como para ser elegida y retratada sistemáticamente por la mayoría de las cecas costeras, de vocación marítima y comercial, de la Ulterior-Bética.

Así, desde las primeras emisiones, Melkart-Herakles se muestra como principal imagen en la que se ampararán las monedas acuñadas que buscan beneficiarse del prestigio de su representación. Asimismo, la divinidad remite al Santuario gaditano, así como a sus conocidas aventuras mitológicas en el Occidente, por lo que demarca fácilmente la ubicación geográfica de las cecas que acuñan su imagen, es decir, contiene en su genealogía simbólica una alusión a una zona muy concreta del Mediterráneo, la Ulterior-Bética, donde se encontraban las Columnas de Hércules y el Santuario que guardaba las cenizas del dios. Esta alusión geográfica era interesante mercantilmente, ya que uno de los principales móviles para la elección de las imágenes que se grabarán en los cuños monetarios era atraer a los comerciantes, así como servir de emblema o carta de presentación de la ciudad en otros confines. Esta función la desempeñará, en gran parte de las cecas de la Bética costera, Melkart-Herakles.

Sin embargo, las ciudades van a individualizar un tipo que en principio parece el mismo. Aunque se trate de la misma divinidad, no se va a perder la personalidad de cada localidad que lo escoge, pues éstas se valdrán de diversas herramientas para dejar traslucir sus diferencias. Así, pueden encontrarse diferentes combinaciones de los atributos del dios, diferentes estilos de representación de la misma divinidad, así como la exageración u omisión de algunos caracteres de la deidad. La clava sola, en reverso, fue un tipo utilizado por Seks (CNH. 104.4, 107.27 y 28) y Carteia (CNH 413.5 y 6, 414.16 y 18, 419.59 y 60) a imitación de los tipos helenísticos y africanos, que no aparecerá en Gadir, ceca que en principio no la utiliza, pero que más tarde la colocará delante del dios y, posteriormente y de forma canónica, sobre su hombro. El estilo helenístico de representación de la deidad predominará en las cecas costeras, pero también se va a utilizar la efigie llamada "africana», a veces barbada y siempre desnuda, de Melkart-Herakles que cecas como Abdera (CNH 113.13-15, 114.16-17) y Seks (CNH 103.1, 104.2-3) utilizan para remarcar su adscripción cultural semita. Gadir en su acuñación se inclina más por mostrarse como una ciudad-estado helenística que como antigua colonia fenicio-púnica. Pese a todo, Gadir exagera una serie de rasgos del dios a los que el resto de cecas no parecen sensibles, como el nudo hercúleo (como ejemplo, $\mathrm{CNH}$ 83.2) o la representación frontal ( $\mathrm{CNH} 85.22-27)$. Será una firma caracterís- 
tica que conscientemente imprime a la imagen, para señalar la autenticidad y originalidad de la misma.

En este sentido, la dudosa iconografía de Helios-Gorgona utilizada en Gadir (CNH 84.14-15, 85.28, 86.29, 87.43-44, 88.45-46) participa también de los tipos empleados dentro de la koiné helenística (Alfaro 2004). A pesar de las dificultades de identificación del tipo, parece que se trata de una representación basada en un culto indígena que se transforma y adapta a las tendencias iconográficas helenísticas.

Malaca será una ceca que durante toda su historia mantiene la peculiaridad de no participar de la representación general de la Bética costera de Melkart-Herakles. Se mantendrá mucho más fiel a su origen fenicio-púnico, utilizando una iconografía muy semita, aunque, con el tiempo, tamizada por el helenismo y la romanización. Sin embargo, las primeras emisiones aún no muestran estas asimilaciones y presentan una tipología muy personal, un tipo egiptizante en anverso que esconde un antiguo culto indígena, acompañado en reverso por una representación anicónica astral, la estrella de diverso número de puntas (CNH 100.1-5). Resulta en conjunto una iconografía que goza del más típico lenguaje púnico (Campo y Mora 1995).

Por tanto, en el siglo III a.C. encontramos una iconografía personal, basada en elecciones particularistas, con tintes indígenas y púnicos y más o menos condicionada por el lenguaje helenístico que, poco a poco y con distintos ritmos dependiendo de cada ceca, va a inundar el Occidente costero. En esta iconografía tan temprana no pueden encontrarse aún las consecuencias de la conquista romana, ya que ésta se produjo al finalizar la tercera centuria; sin embargo, tampoco se trata de una tipología aislada y única en el Mediterráneo, deriva, más bien, de una participación de los estereotipos preexistentes bien conocidos dentro del helenismo que las cecas escogen y adaptan a sus necesidades (Fig. 2).

\section{LAS HUELLAS DE LA CONQUISTA ROMANA: EL SIGLO II a.C.}

Los primeros indicios de la romanización pueden rastrearse en la Ulterior desde el siglo II a.C. En estos momentos, las cecas litorales eligen libremente los tipos que acuñarán, aunque, pese a esta supuesta libertad, comenzarán a transformar sus imágenes añadiendo rasgos típicamente romanos (Tabla 2). Las culturas prerromanas se conservarán con vitalidad hasta época imperial, lo cual se desprende del mantenimiento en la moneda de su propio sistema de valores, escrituras y lenguas, así como de la representación de divinidades autóctonas y de sus rituales en la tipología monetaria escogida, que demuestra la existencia en Hispania de comunidades púnicas (García-Bellido y Blázquez 2001).

Roma confirió absoluta libertad a las cecas hispanas para utilizar en su amonedación caracteres externos culturales, escritura, metrología, iconografía... que claramente demostraban su profundo arraigo político y cultural con sus enemigos púnicos. En estos momentos tempranos, Roma necesita autoafirmarse en su pro- 


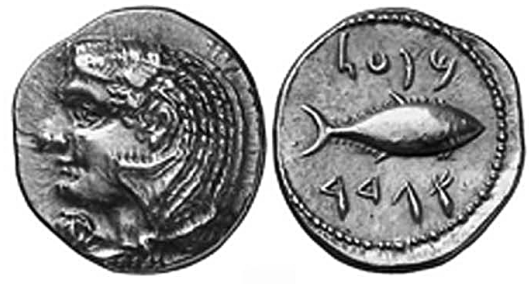

1

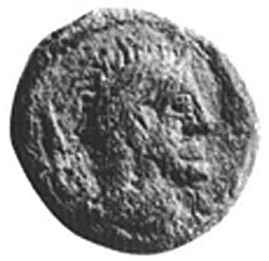

3
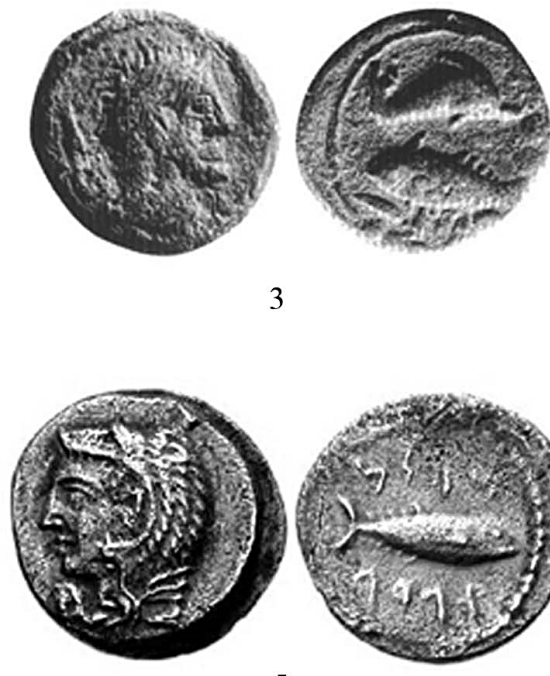

5

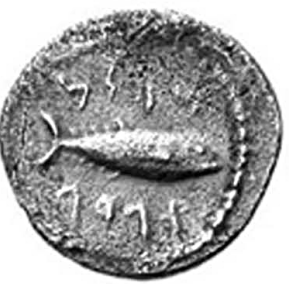

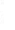
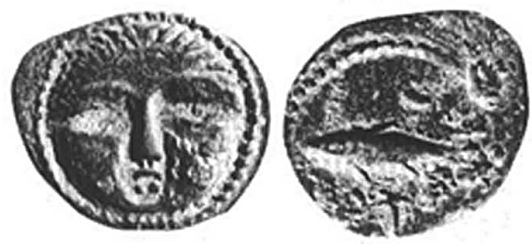

7

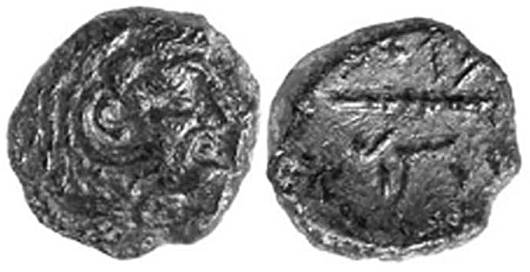

2
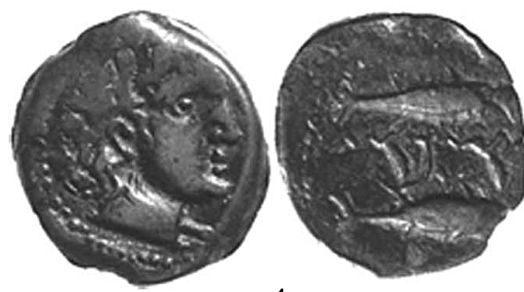

4

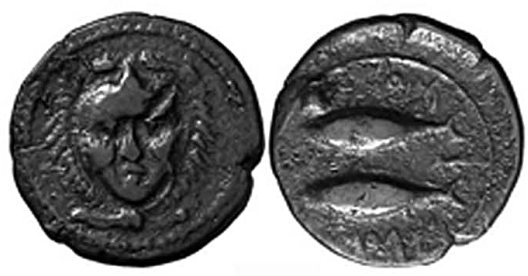

6
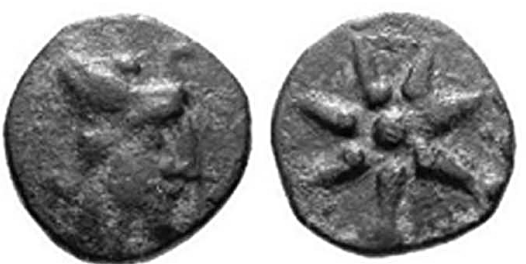

8

Fig. 2. Ejemplos de la amonedación de la Ulterior costera durante el siglo III a.C.

1. Gadir (CNH 82.1): Anv. Cabeza de Melkart-Herakles tocado con leonté a izquierda. Rev. Atún a derecha, encima MHLM y debajo ‘GDR; 2. Seks (CNH 104.4): Anv. Cabeza de Melkart - Herakles tocado con leonté a derecha. Rev. Clava horizontal, encima MP'L, debajo, SKS; 3. Abdera (CNH 114.16): Anv. Cabeza de Melkart a derecha, clava detrás. Rev. Delfín a derecha, debajo atún a izquierda. A derecha, dos glóbulos, debajo, 'BDRT; 4. Seks (CNH 103.1): Anv. Cabeza de Melkart a derecha, clava detrás. Rev. Dos atunes a derecha, en medio SKS; 5. Gadir (CNH 83.2): Anv. Cabeza de Melkart - Herakles a derecha con leonté. Rev. Atún a derecha, encima MHLM y debajo 'GDR; 6.

Gadir (CNH 85.27): Anv. Cabeza de Melkart - Herakles con leonté de frente. Rev. Dos atunes a derecha, encima MP'L, debajo, 'GDR; 7. Gadir (CNH 87.44): Anv. Cabeza de ¿Helios? de frente. Rev. Atún a izquierda, debajo ALEPH; 8. Malaca (CNH 100.2): Anv. Cabeza viril con petaso/tiara doble egipcia a derecha. Rev. Estrella de siete puntas. 
La imagen proyectada por la Bética costera durante los siglos II a.C a I d.C.

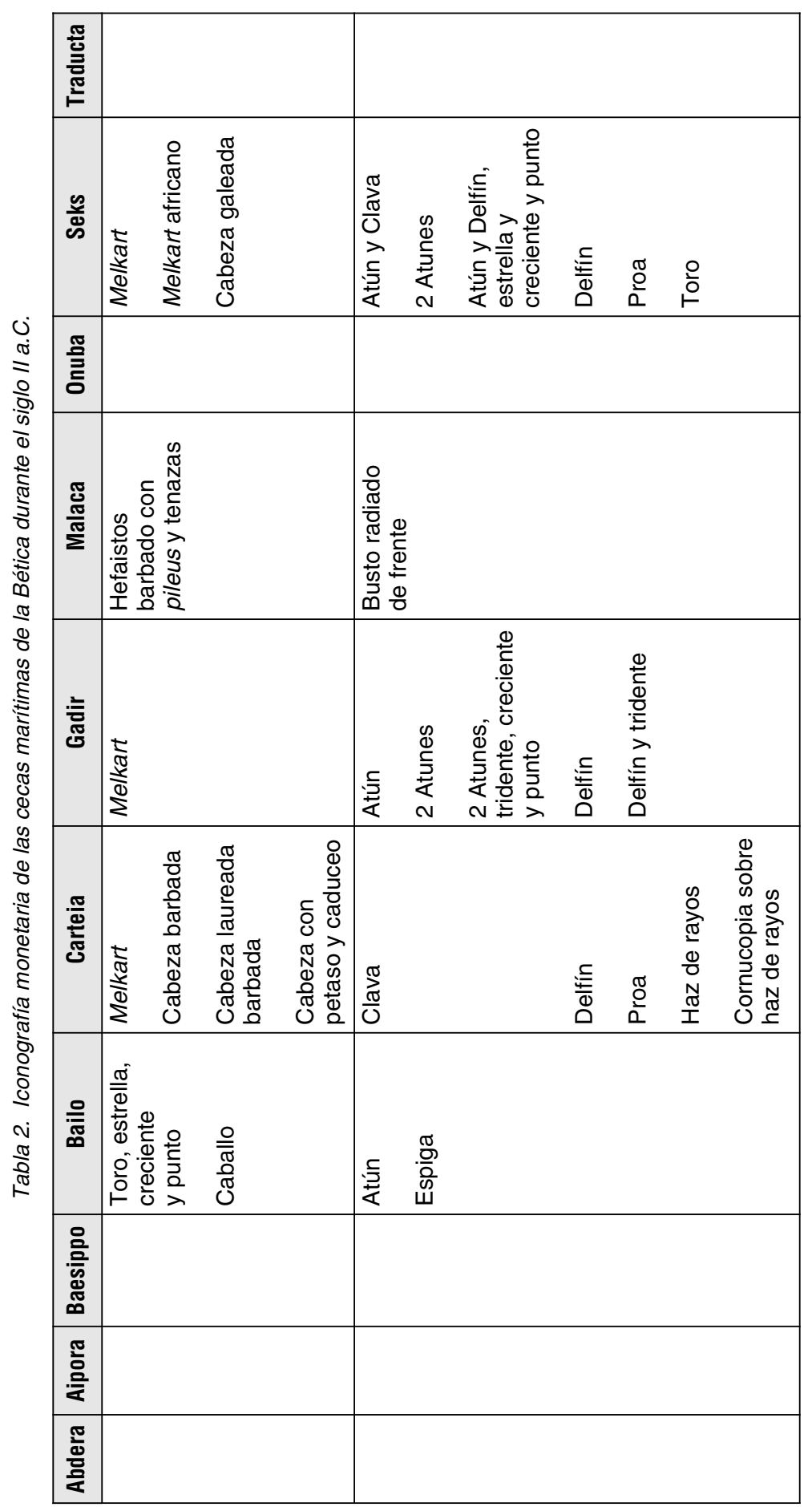


pia cultura, exaltando las diferencias con el resto de pueblos del Mediterráneo que, dentro de su particular ideología y visión del mundo, la hacen única, grande y merecedora de la victoria en la batalla. Roma precisa aún justificar por qué es digna de poseer el enorme Imperio que en estos momentos se está forjando, tanto para su propio pueblo como para las gentes externae o barbaroi. Una de las herramientas que utilizará para este fin será la expresión iconográfica. El conceder plena libertad en la elección de los tipos a Hispania y a otras provincias le otorgará una ventaja tan importante como simple, la diferenciación cultural.

Durante el siglo II a.C. Gades mantiene en anverso la imagen de Melkart-Herakles en un perfil que se ha llegado a llamar «tipo inmovilizado» (CNH 86.35-36, 87.37-42, 88.47-52, 89.53-57). Sin embargo, los cambios respecto al siglo anterior son evidentes. Los cuños de cuidado estilo helenístico van a dejar paso al «estilo romano» (Alfaro 1988). Este cambio en la ejecución del trazado del dios es muy significativo, pues demuestra la interesante y hábil decisión política que Gades va a llevar a cabo. Olvidando su tradicional alianza púnica, abandonada tras la guerra, Gades se inclina ahora por escoger una tipología que remita a su nueva situación política, firmada en el foedus con Roma. Remitiendo al nuevo ambiente y contexto histórico, los tipos van a romanizarse formalmente en su trazado, aunque en su esencia mantendrán la misma finalidad y alusiones simbólicas. Por tanto, la iconografía va a demostrar un cambio consecuente dentro de la realidad cambiante del siglo II a.C. Se trata de los mismos tipos pero se presentan con un tratamiento distinto, este cambio estilístico es consciente y no debe tomarse a la ligera. La asunción de este carácter latino implica la aceptación de la autoridad romana en aspectos tan íntimos y personales como la ejecución de los rasgos de la divinidad, ya que, a su vez, esta misma imagen es enseña y distintivo de la ciudad para con el exterior y transmite la idea que el Estado gaditano quería proyectar de sí mismo. Así, Gades continua representando su propia tipología, escogida por la ceca desde antiguo y con la misma intencionalidad y simbología, pero que ahora se graba de una forma diferente, significando la inclusión de la ciudad en el nuevo orden político mediterráneo que lideraba Roma.

Este mismo esquema va a seguirse por el resto de las cecas de la costa Ulterior. Se tomarán los tipos propios de la ciudad y se les imprimirán alusiones a la dominación romana, adaptando la iconografía tradicional al nuevo contexto. Seks (CNH 107.26-28) salvaguarda su carácter semita al mantener la representación de Melkart africano, acompañado por atunes y delfines así como de creciente y punto, que remitirá a las estrechas relaciones económicas, poblacionales y religiosas del Círculo del Estrecho (Sur de la Bética-Norte de África). Sin embargo, va a aparecer en este momento un nuevo tipo, la cabeza galeada (CNH 106.17-19, 107.24$25,29)$, que, sin dejar de adscribirse fácilmente a la koiné helenística y púnica, remite a las cabezas de Dea Roma de las monedas oficiales republicanas. Esta inclinación por la iconografía romana se encuentra también en las proas de guerra acuñadas tanto en Seks (CNH 106.23, 24) como en Carteia (CNH 413.10, 414.1415, 17-19, 21415.22-26, 28-30, 416.35-40 417. 41-44, 46-47), copia de los conocidos tipos romanos, Jano bifronte y proa, que aluden a la fuerza bélica marítima de la potencia conquistadora. La asunción de esta imagen tan típicamente romana 
y de carácter tan bélico supone para Seks la confirmación de su adscripción política al nuevo Imperio, es un movimiento de buena voluntad por parte de la ciudad, que espera una recompensa traducida en privilegios y mejoras en la condición política de la ciudad.

Malaca se une a esta corriente transformando sus tipos en un lenguaje típicamente helenístico que no deja de aludir al carácter semita de la ciudad. Ésta será la ceca que más fielmente se mantenga a sus orígenes, ya que, pese a la contaminación helenística de su iconografía, ésta siempre va a contener un significado púnico. El «tipo del faraón» se abandona en estos momentos a favor de una imagen canónica de Hephaistos-Vulcano (CNH 100.9, 101.10-14) que posiblemente responda a una traducción al estilo helenístico de una divinidad metalúrgica indígena púnica anterior, quizá Chusor-Ptah. Se escoge para ello la iconografía canonizada del dios, tocada con pilleus, barbado y con tenazas, es la típica imagen del dios de la siderurgia que ya se había utilizado en otras ciudades mediterráneas, como Hephaisteia (Lemnos). En reverso, se escoge una imagen que no resultaba tampoco extraña en el Mediterráneo, al contrario, el busto radiado vestido con capa drapeada sujeta por broche circular fue una representación de Apolo-Helios muy utilizada durante el helenismo; sin embargo, la imagen malacitana contiene rasgos muy personales de la ceca que hacen difícil su identificación, ya que contiene peculiaridades que remiten a una posible divinidad semita de culto ancestral en la ciudad (Campo y Mora 1995).

Por tanto, se toman tipos preexistentes y se adaptan y transforman para adecuarlos a la personalidad de cada centro emisor. No es una copia exacta y literal, sino muy asimilada a los gustos de las cecas, que hábilmente fusionan sus sentires púnicos a la universalidad proyectada por las imágenes de todo el Mediterráneo. Hay una tendencia a la homogeneización de los tipos; sin embargo, de entre la abundante iconografía a disposición de las cecas se escogen las imágenes que concentran mejor la idea de una personalidad individual de cada ceca dentro de la unidad política e ideológica del Imperio Romano.

La ceca que más hábilmente combina estos dos factores será Carteia (Chaves 1979a). Por su carácter de colonia romana fundada con población tanto itálica como indígena, esta fusión resulta natural para ella. Escoge los tipos que más naturalmente se adecuan a su peculiar personalidad; las cabezas barbadas y laureadas (CNH 412.1, 413.4, 7-12, 414. 13-21, 415.22-30, 416.31-34, 416.37-40, 417.41-43, 418.55-57), sistemáticamente utilizadas por la ceca, son tan romanas como púnicas, porque participan de la iconografía general del «dios senex», venerable y anciano, pero fuerte y poderoso, caracteres tanto de Baal Hammon como de Zeus-Júpiter y Poseidón-Neptuno. Hay que valorar estas representaciones como una fusión de todos estos elementos, fusión que explica visualmente la evolución que sufrió la religión griega y púnica durante el helenismo, corriente que supuso asimilaciones, sincretismos y contaminaciones de las diferentes creencias mediterráneas y que se tradujo en la conformación de lo que llamamos la koiné mediterránea. 
Ciudad marítima y comercial habitada tanto por colonos romanos como por libertos nacidos en la Península Ibérica, Carteia fue una localidad con un núcleo cultural púnico al que se suman las nuevas influencias romanas traídas por los itálicos, aunque la mayoría de la población de las clases populares se encontraría inmersa en la tradición púnica. Los tipos que acuña están cuidadosamente elegidos para responder al peculiar carácter de sus habitantes. Sobre una iconografía de aspecto romanizado (cabeza barbada, cabeza de Hermes-Mercurio, proa, fulmen, cornucopia), se superpone un significado púnico ${ }^{2}$ que aúna en una misma imagen la tradición con la adscripción política y cultural a Roma. Su estatuto superior, como primera colonia romana fuera de Italia, así como la presencia de población itálica entre sus murallas, se plasma en el intento de asimilarse a la capital al elegir sus mismos tipos.

En general, la imagen proyectada por las monedas de la Bética costera en el siglo II a.C. demuestra una incipiente inclusión en los valores romanos sin dejar en ningún momento de aludir al origen púnico de sus ciudades. Es un período interesantísimo en la conformación de la provincia Ulterior donde la iconografía se corresponde exactamente con el momento histórico que se está viviendo. El cambio iconográfico es sutil pero supone una importante diferencia iconológica con respecto a la etapa anterior (Fig. 3).

\section{LA GENERALIZACIÓN DE LAS ACUÑACIONES: EL SIGLO I a.C.}

La primera mitad del siglo I a.C. supuso un paso más en esta evolución. (Tabla 3). Es el momento en el que acuña el mayor número de cecas costeras y lo hacen manteniendo la tendencia general del siglo II a.C.: fuerte influencia del mar, así como una fusión entre los caracteres romanos y púnicos a través de un lenguaje típicamente helenístico. Abdera (Alfaro 1996) se une en estos momentos a la acuñación y utiliza tipos basados en la iconografía de Seks: Melkart-Herakles africano (CNH 113.13-15, 114.16-17), cabeza galeada (CNH 112.5-6, 113.7-12), atunes y delfines. Una vez más, tipos tradicionales, frecuentemente utilizados en la Bética desde antiguo, tamizados por la iconografía romana.

La acuñación de Malaca es muy interesante porque demuestra enérgicamente en este periodo un paso más en el avance de sus tipos hacia la romanización. Cambia la tradicional imagen de Hephaistos-Vulcano por un tipo, que, participando de su misma iconografía, era mucho más cercano a Roma, los Cábiros-Dióscuros (CNH 102.23-25, 103.26-27) (Campo y Mora, 1995), héroes que se representaban con asiduidad en las monedas de la República por su relación con la fundación de

2 La imagen de Hermes-Mercurio que Carteia acuña podría ser la de Mercurio Africano, cuya principal diferencia es su carácter agrícola, aunque sus funciones como mensajero de los dioses serían las mismas. En el Norte de África se encuentran gran cantidad de dedicaciones a esta divinidad con un escorpión como atributo y acompañado de espigas. Por tanto, existía una divinidad púnica anterior fácilmente asimilable a Mercurio y que podría aparecer en Carmo como un dios joven, imberbe, tocado con petaso y acompañado en reverso de caduceo o espigas, en Abdera, como una cabeza masculina con petaso, y en Carteia, con haz de rayos y caduceo. 


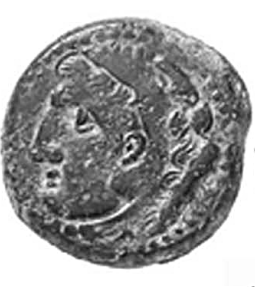

1

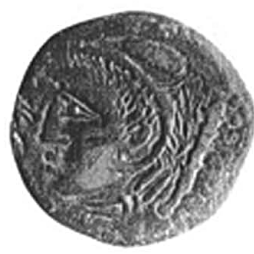

3
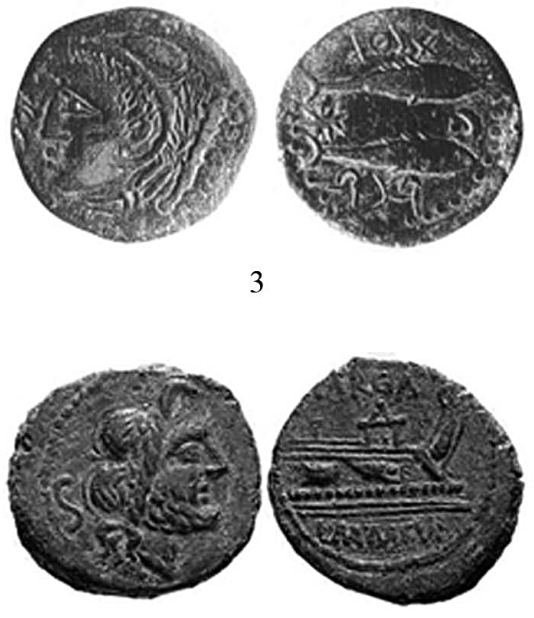

5

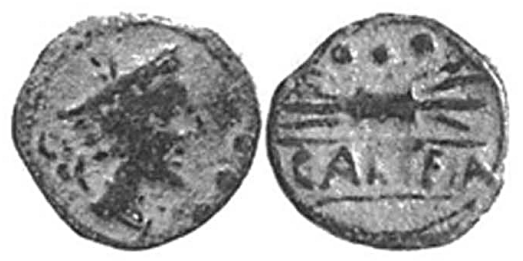

7

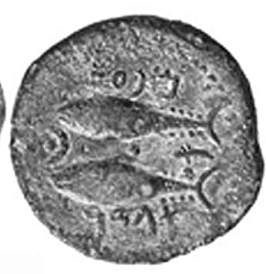

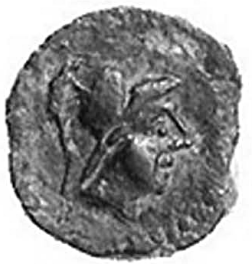

4

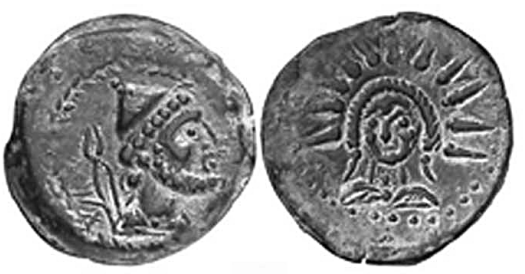

6

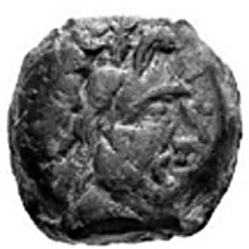

8
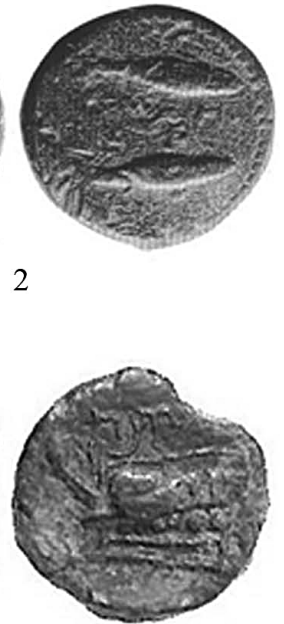

2

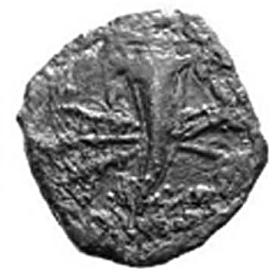

Fig. 3. Ejemplos de la amonedación de la Ulterior costera durante el siglo Il a.C.:

1. Gades (CNH 86.5): Anv. Cabeza de Melkart - Herakles con leonté a izquierda, detrás, clava. Rev. Dos atunes a izquierda, entre ellos, creciente con un punto, ALEPH y, en medio, glóbulo. Encima MP'L. Debajo, 'GDR; 2. Seks (CNH 107.26): Cabeza barbada de Melkart, detrás, clava. Rev. Dos atunes a derecha, en medio SKS; 3. Seks (CNH 104.5): Cabeza de Melkart - Herakles con leonté a izquierda y clava detrás. Rev. Dos atunes a derecha, en medio, estrella y creciente con astro. Encima, MP'L, debajo, SKS; 4. Seks (CNH 107.24): Anv. Cabeza con casco con penacho a derecha. Rev. Proa a izquierda, encima, SKS; 5. Carteia (CNH 414.14): Anv. Cabeza barbada a derecha. Detrás S. Rev.

Proa a derecha. Delante, S. Encima L MARC. Debajo, CARTEIA; 6. Malaca (CNH 100.9): Anv.

Cabeza barbada con gorro cónico a derecha. Detrás MLK' y tenazas. Alrededor láurea. Rev. Busto radiado de frente; 7. Carteia (CNH 412.2): Anv. Cabeza de Mercurio con petaso a derecha. Detrás, caduceo, delante, tres glóbulos. Rev. Haz de rayos, encima, tres glóbulos, debajo, entre líneas,

CARTEIA; 8. Carteia (CNH 413.7): Anv. Cabeza barbada y laureada a derecha. Rev. Cornucopia sobre haz de rayos, arriba, a izquierda, S, abajo, a izquierda, $Q$ y a derecha, Q CURVI. 


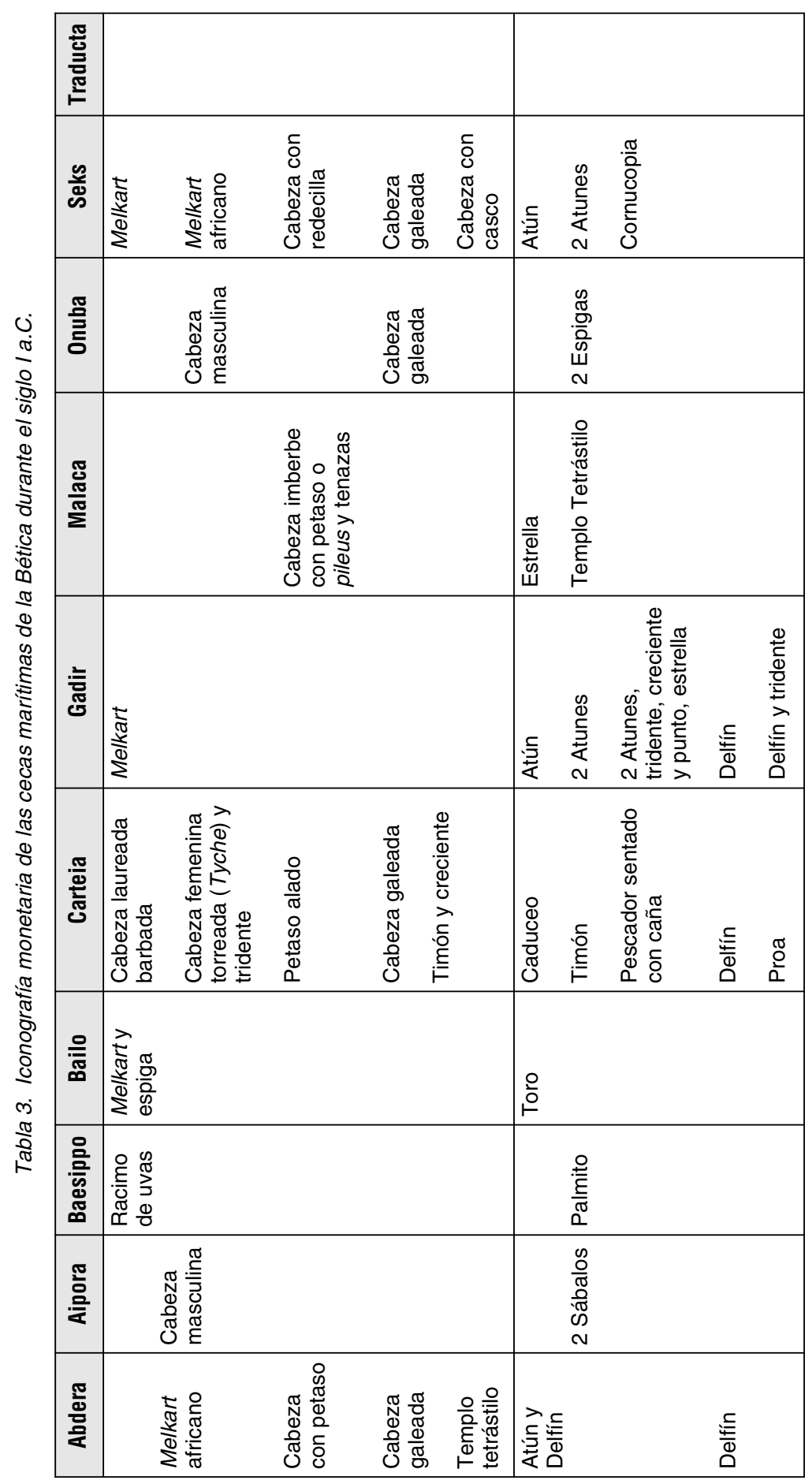


Roma. Esta elección refleja una inclinación por los tipos romanos en conflicto con la tradicional iconografía de la ciudad. Esta misma situación se refleja al sustituir la imagen de la estrella, auténtico emblema malacitano, por el templo tetrástilo $(\mathrm{CNH}$ 101.15-17, 102.18-20), tipo estereotipado que se utiliza, a diferencia del astro, como tipo principal por varias cecas costeras béticas. Ya no es un tipo personal, sino, más bien, es una imagen monetaria canónica que pierde la fuerza semita que Malaca insuflaba a sus tipos desde antiguo.

Las acuñaciones de Onuba (CNH 387.1-4, 388.5-7) y Baesippo (CNH 408.1) se alejan de la personalidad costera del resto de las acuñaciones y se asemejan más a la iconografía del interior y del Valle del Betis, con la representación de espigas y racimos de uvas. Sin embargo, también puede apreciarse cómo escogen tipos canónicos y estereotipados utilizados en el Norte de África, confirmando así los vínculos entre ambos lados del Estrecho de Gibraltar, así como en los estados griegos y púnicos mediterráneos. La espiga fue un símbolo relacionado con la fertilidad y la fecundidad muy frecuentemente representado en la Antigüedad, se utilizó en relación a Ceres, Deméter, Tanit e incluso Melkart-Herakles. Efectivamente, su alejamiento de la temática marina no lo aparta del catálogo de tipos que muestra la acuñación mediterránea, es más, la espiga fue uno de los motivos vegetales representados más habitualmente y con mayor gusto, pues representaba todo un estilo de vida basado en la agricultura, consumo y comercialización del cereal. El sentido económico imprimido en esta tipología se funde con el sentido religioso que este producto exhibía desde los inicios de su cultivo, de esta forma, es símbolo de multitud de divinidades y se comprende como atributo de todas ellas, aunque la maternal divinidad femenina, Tanit en el caso púnico y semita, será la que exprese con mayor fuerza todo el contenido simbólico de esta iconografía.

El caso de la espiga trazada en el tipo de Melkart-Herakles de Bailo (CNH 130.3) es muy interesante, pues retoma un aspecto del dios no explotado por el resto de las cecas béticas costeras. Sin embargo, el trigo no era un elemento ajeno a esta divinidad, ni en su advocación griega ni en la púnica. Melkart-Herakles fue representado junto a la espiga en múltiples ocasiones, aludiendo al carácter pasional de la divinidad púnica. Este rasgo ancestral del dios se mantiene en Bailo, ciudad que funde los tipos que utilizó en la etapa anterior para crear una nueva iconografía que recogiese el carácter agrícola y marítimo de la ciudad.

Carteia en esta etapa mantendrá la tendencia que había iniciado en el periodo anterior. Conserva la tipología del siglo II a.C. a la que añade nuevos tipos con gran personalidad, como el pescador sentado con caña (CNH 418.51-53, 420.6970). La polémica sobre la influencia de Pompeyo en los tipos de la ciudad deberá ser contrastada por la Arqueología (Roldán et alii, 2003), así como por el estudio de los cuños y de las pervivencias de circulación residual monetaria, que podrán aclarar si la ceca se cerró o no durante un breve lapso de tiempo como castigo por su afiliación al bando pompeyano (Chaves 1979b). Su iconografía en el tránsito del fin de la República y los inicios del Imperio muestra la asunción de los tipos marítimos que Pompeyo había utilizado en su programa propagandístico de exaltación a su persona. El tipo más acorde con esta tipología fue la imagen de Poseidón- 
Neptuno estante con delfín y tridente en sendas manos (RPC 122), esta tipología fue coyuntural, no se encuentra en la iconografía de la etapa anterior (pese a las constantes referencias al dios del mar, posible divinidad patrona de la ciudad) y desaparece completamente de las emisiones de la ciudad durante el principado. El cambio iconográfico que se aprecia durante el Imperio es muy importante, la ciudad inventa nuevos tipos, recarga los ya existentes y elimina las posibles referencias a Pompeyo, aunque se mantiene fiel a su esencia marítima y púnico-romana. No obstante, podría decirse que en estos momentos el lenguaje que se utiliza es más romano que semita y expresa el deseo de la ciudad por asumir completamente la identidad itálica que el Imperio le ofrece como colonia y ciudad privilegiada. Al mismo tiempo, el estudio de los detalles de la iconografía carteiense muestra una fuerte personalidad e individualidad con respecto al resto de las cecas de la costa bética, así como un alejamiento de la generalidad iconográfica que ostentaba la aceptación del culto imperial y la política dinástica de Augusto.

La imagen general que la Bética proyecta en estos momentos muestra cómo se mantienen los tipos tradicionales más canónicos, como Melkart-Herakles, atunes, delfines, cabezas galeadas, proas, cornucopias, caduceos, timones... tipos helénicos estereotipados, que en última instancia eran comprendidos por Roma, ya que ella, en general, también los había utilizado. Junto a ello, existen otros tipos como los Cabiros-Dióscuros de Malaca, el templo tetrástilo abderetano ( $\mathrm{CNH}$ 112.1-4) o la cabeza torreada en Carteia (CNH 417.50, 418.51-54, 419.58-61, 65-66, 420.67, 69-71), que, derivados de una iconografía anterior, aparecen en estos momentos y buscan un acercamiento al lenguaje romano sin perder la personalidad ciudadana. (Fig. 4).

\section{EL ADVENIMIENTO DE UN NUEVO ORDEN: EL IMPERIO}

La llegada del Imperio supondrá la asunción definitiva de los tipos romanos gracias a la propaganda imperial de Augusto (Tabla 4). La personalidad de cada una de las cecas se mantiene, pero se reviste de una expresión típicamente romana. Harán su aparición tipos que nunca antes se habían acuñado, como el acrostolium, aplustre, signos pontificales, simpulum, ápex, pátera, lira, etc. Los retratos imperiales surgen en las cecas de Abdera (RPC 124 y 126), Gades (RPC 80-81, 83-84, 88-90, 95-97), Traducta (RPC 98-105, 107-110) y, según Campo y Mora (1995), Malaca (CNH 100.7). Se acompañarán de símbolos típicamente itálicos referidos a la victoria de Augusto y su pontificado, asimismo, se le representará como Divus Augustus, en una clara referencia al culto imperial. Signo inequívoco de la plena aprehensión del espíritu de la política dinástica, los herederos de Augusto desfilarán por los anversos y reversos de las monedas béticas costeras. No obstante, en esta nueva realidad política cada ciudad es capaz de tomar sus tipos tradicionales y transformarlos para que, sin dejar de ser los mismos, se fundan en el lenguaje imperial y aludan, a su vez, al Imperio y a los orígenes de la ciudad. Ejemplo de ello es el templo de columnas tuniformes de Abdera (RPC 124-126), que funde en un mismo tipo la iconografía de los atunes y del templo tetrástilo (Al- 

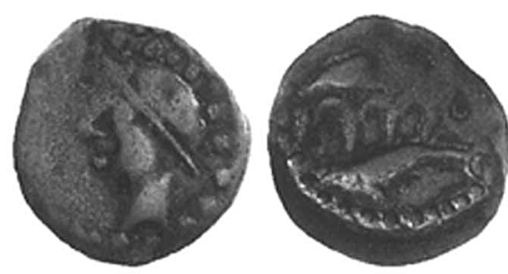

1

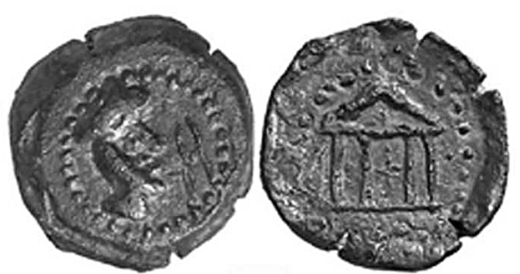

3

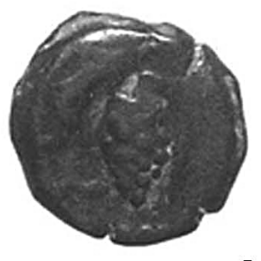

5
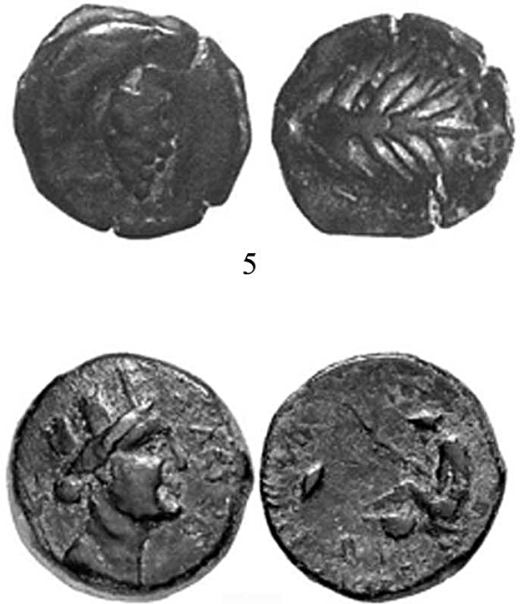

7

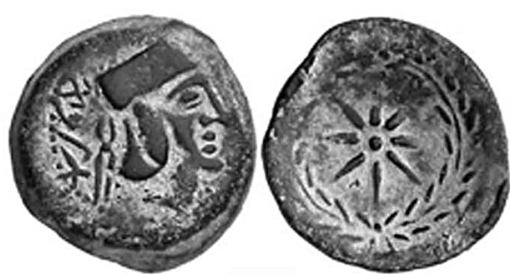

2
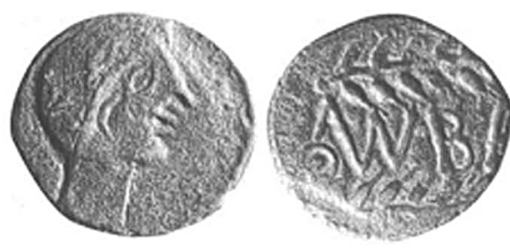

4

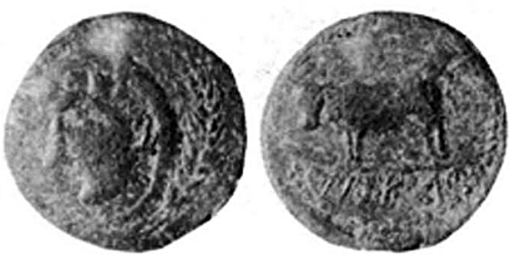

6
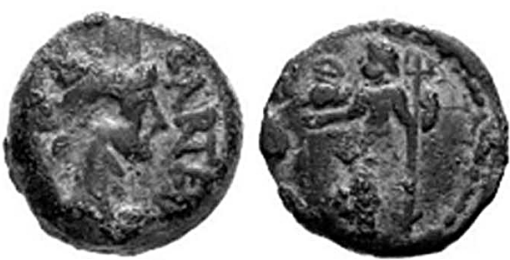

8

Figura 4. Ejemplos de la amonedación de la Bética costera durante el siglo I a.C.

1. Abdera (CNH 112.5): Anv. Cabeza galeada a izquierda. Rev. Atún y delfín. En medio, 'BDRT; 2. Malaca (CNH 102.23): Anv. Cabeza masculina imberbe con petaso a derecha. Detrás leyenda púnica MLK' y tenazas. Rev. Estrella de ocho puntas dentro de láurea; 3. Malaca (CNH 102.19): Anv. Cabeza masculina imberbe con petaso a derecha. Detrás, MLK' y tenazas. Rev. Templo tetrástilo; 4. Onuba (CNH 387.2): Anv. Cabeza a derecha. Rev. Dos espigas a derecha, en medio, ONVBA; 5. Baesippo (CNH 408.1): Anv. Racimo de uvas, detrás, serpentiforme. Rev. Palmito tendido, debajo, BAICIPO; 6. Bailo (CNH 130.3): Anv. Cabeza de Melkart - Herakles con leonté a izquierda, detrás, izquierda. Rev.

Toro a izquierda, debajo, leyenda libiofenicia no leída; 7. Carteia (CNH 418.52): Anv. Cabeza

femenina torreada a derecha (Tyche/Tanit). Detrás, tridente. Delante, interior, CARTEIA. Rev. Pescador sentado sobre rocas a izquierda sosteniendo una caña de la que pende un pez. Debajo, C MINI IV / C VIBI IV. Detrás, IIII VIR; 8. Carteia (RPC 122): Anv. Cabeza femenina torreada a derecha (Tyche). Delante, interior, CARTEIA. Rev. Poseidón - Neptuno desnudo y de pie a izquierda. Pierna derecha sobre roca, sostiene un tridente en la mano izquierda y un delfín en la derecha. Delante, D. D. 
ELENA MORENO PULIDO

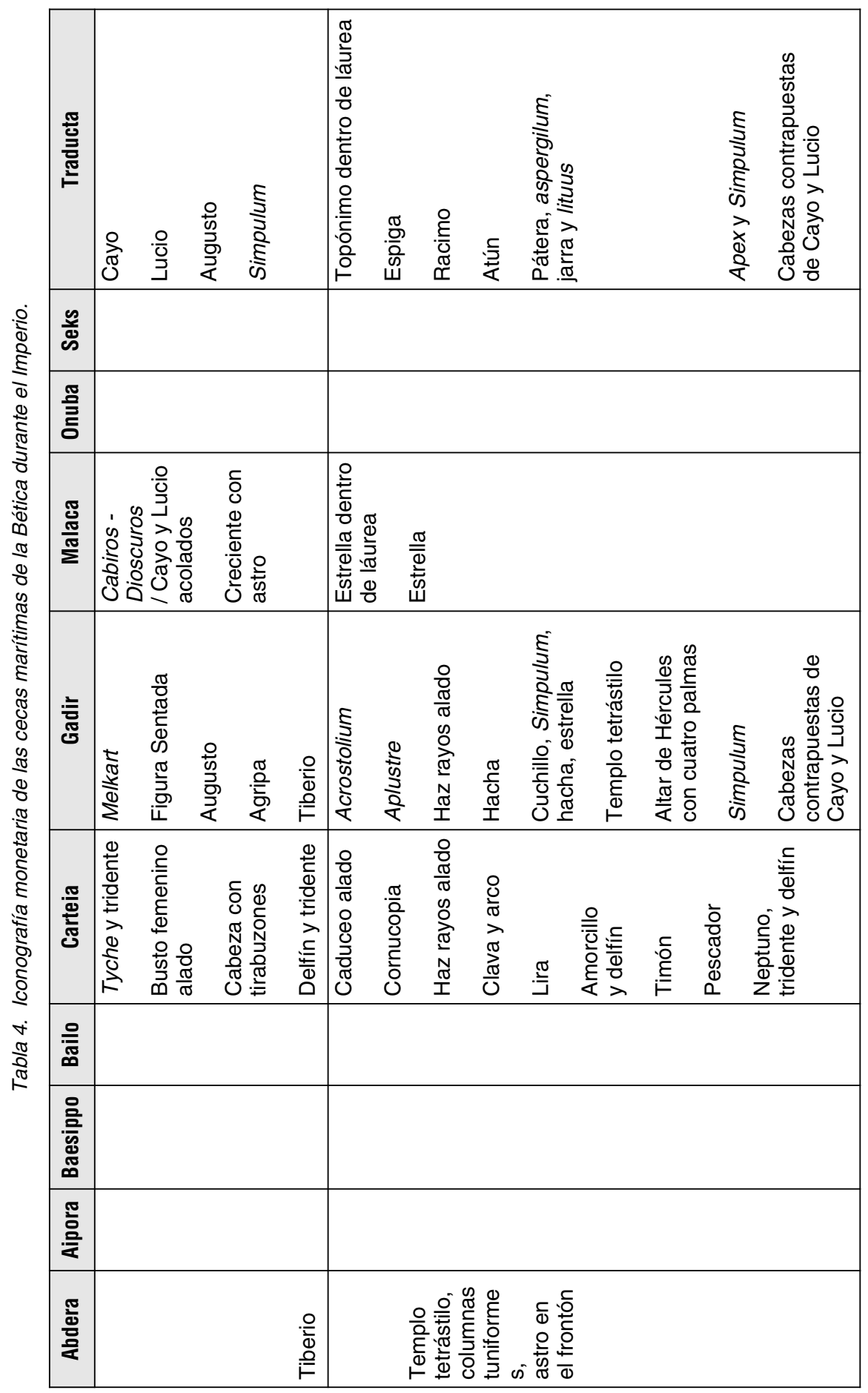


faro 1996). Carteia opta por recargar sus tipos tradicionales para, sin dejar de ser los suyos propios, asimilarlos al lenguaje romano, de esta forma, se presenta, entre otros, el tipo de amorcillo cabalgando sobre delfín (RPC 116-118).

Gades alternó la imagen de Melkart-Herakles que había esgrimido durante toda su amonedación con una tipología de lenguaje netamente romano. El recurrente tipo de los atunes, así como el delfín, desaparece a favor de los instrumentos litúrgicos que exhibían los logros de los personajes más destacados del momento, el pontificado de Balbo (RPC 85-87), el patronato de Agripa (RPC 78-84) y al emperador Augusto como Divus Filius y Pontifex Maximus (RPC 92-94). Política y propaganda imperial inundan la iconografía de Gades, que apenas había sufrido alteraciones durante casi dos siglos. La ciudad quiere expresar su cercanía y la aceptación del nuevo orden de Augusto, por lo que recurre a los personajes que tendían lazos entre ella y el Princeps. El lenguaje utilizado expresa el deseo de manifestar la asunción de la cultura romana como medio de prestigiar la ciudad y presentarla al mundo exterior como plenamente integrada en la estructura del Imperio. No obstante, la historia que vinculaba a Gades con Melkart-Herakles no se olvida, la importancia del dios no declina y su Santuario seguirá siendo un referente para el mundo occidental. De esta forma, el tipo canónico de Hércules Gaditanus se utiliza en la última emisión de la ciudad y sigue vivo y con fuerza incluso en emisiones romanas durante el Alto Imperio ${ }^{3}$.

Por tanto, en general, el Imperio supuso, como no podía ser de otra manera, una etapa con diferencias muy marcadas dentro de la iconografía monetaria de la Bética costera. No puede decirse que la tipología sea muy homogénea, puesto que se advierte en Carteia, Traducta y Gades una diversidad de cuños que hasta entonces no se había observado, sin embargo, el gusto púnico e indígena se mantiene y las cecas se las ingenian hábilmente para camuflar en un lenguaje romano la esencia púnica que aún se mantenía con fuerza (Fig. 5).

\section{ALGUNAS CONCLUSIONES}

Las cecas costeras de la Bética presentan una personalidad muy marcada que justifica un estudio conjunto desde un punto de vista amplio y plural. Para lograr una mejor comprensión de las circunstancias que motivaron cada acuñación, es fundamental tener en cuenta las múltiples relaciones que conforman su idiosincrasia, entre las que destacan los estrechos y continuos contactos con el Norte de África, la fuerte influencia del mar, su origen púnico, las fluctuaciones poblacionales, su compartido contexto histórico y su carácter mercantil. Todos estos factores dan como resultado una iconografía muy peculiar que se diferenciará claramente de la tipología del interior de la Bética. En general, las ciudades costeras se enfrentan a una lucha entre la romanización de los tipos y la conservación de sus ca-

${ }^{3}$ Como sucede en el áureo de Adriano (119-125 d.C.), que muestra en reverso el altar de Hercules Gaditanus, única imagen que conservamos del Santuario de Gades (RIC 156). 

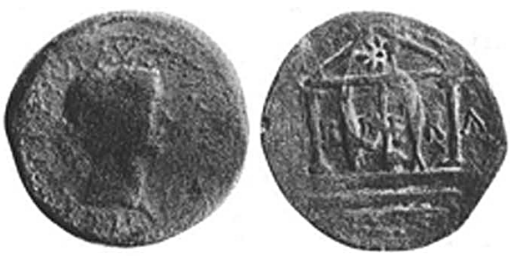

1

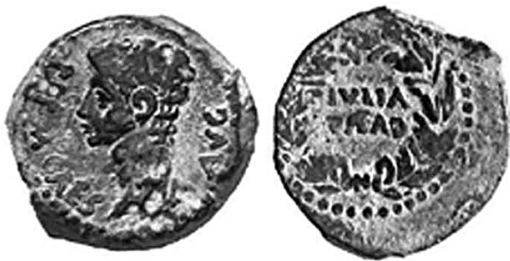

3

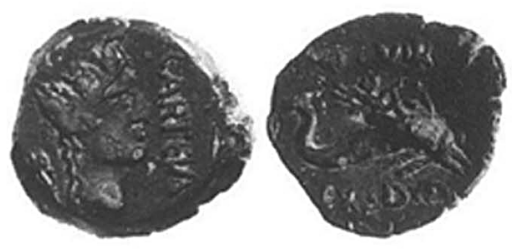

5

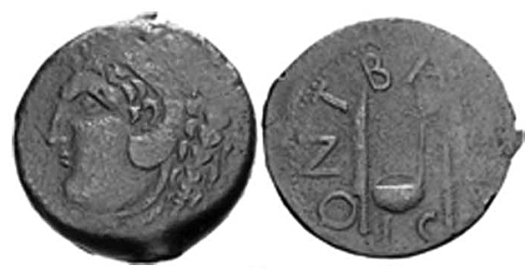

7

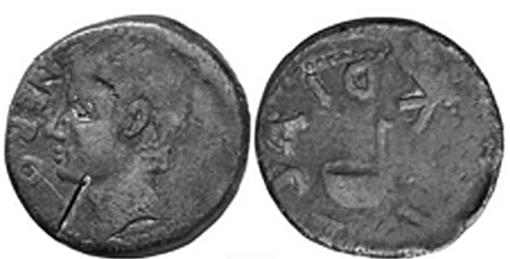

2
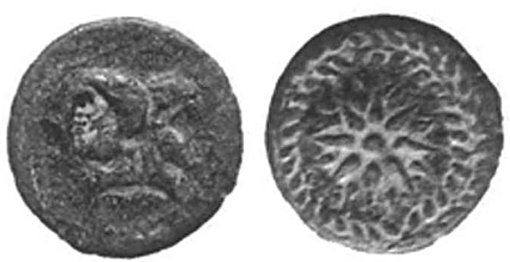

4
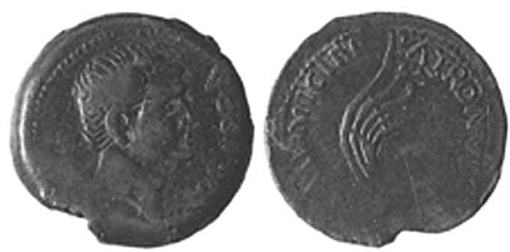

6
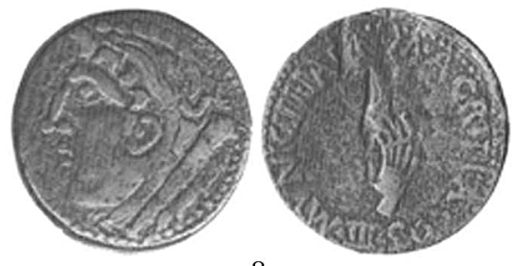

8

Fig. 5. Ejemplos de la amonedación de la Bética costera durante el Imperio.

1. Abdera (RPC 126): Anv. Cabeza laureada de Tiberio a derecha, leyenda interior: TI CAESAR DIVI AUG F AUGUSTUS. Rev. Templo tetrástilo, dos de cuyas columnas son atunes, astro radiado en tímpano. Entre las columnas, A-B-DE-R-A.; 2. Gades (RPC 88): Anv. Cabeza de Tiberio a derecha o a izquierda. Leyenda: NERO. Rev. Simpulum. Leyenda: TI CLAVDIVS; 3. Traducta (RPC 108): Anv.

Cabeza de Augusto a izquierda. Alrededor exterior, PERM CAES AVG. Rev. Corona de roble rodeando IVLIA TRAD; 4. Malaca (CNH 100.7): Anv. Cabezas de Hefaistos y Chusor - Ptah / Cábiros dioscuros / Cayo y Lucio unidas por la nuca. A derecha, tenazas y a izquierda, palma. Debajo, MLK'.

Rev. Estrella de dieciséis rayos dentro de corona vegetal; 5. Carteia (RPC 116): Anv. Cabeza femenina torreada (Tyche). Detrás, tridente. Delante, interior, CARTEIA. Rev. Amorcillo cabalgando sobre delfín a derecha; 6. Gades (RPC 83): Anv. Cabeza de Agripa a derecha. Leyenda AGRIPPA.

Rev. Aplustre. Leyenda: MUNICIPI PATRONUS PARENS; 7. Gades (RPC 85): Anv. Cabeza de Melkart - Hércules con leonté a izquierda y clava detrás. Rev. Cuchillo, simpulum, hacha y, a veces, estrella. Leyenda: PONT BALBVS; 8. Gades (RPC 79): Anv. Cabeza de Melkart - Hércules con leonté a izquierda, clava detrás. Rev. Acrostolium. Leyenda: M AGRIPA COS III MUNICIPI PAREN. 
racteres púnicos, pues los diseños que asumen y exportan son emblema de la ciudad, carta de presentación de la misma para el exterior. Ante esta disyuntiva, eligieron adoptar una posición intermedia; tomaron en préstamo imágenes que circulaban desde antiguo entre las ciudades mediterráneas, cuyo significado se correspondía con su propia idiosincrasia y que resultaba válido para la descripción de cada una de sus diferentes personalidades y lo adaptaron a las necesidades de cada contexto histórico. Las ciudades de la Bética costera apuestan por el sincretismo y la elección de tipologías bien conocidas para crear distintivos ciudadanos fácilmente comprensibles en todo el Mediterráneo. La consecuencia última será una iconografía muy flexible, con carácter propio, a veces disfrazada con un lenguaje helenístico que oculta reminiscencias de los cultos locales y recuerdos de emisiones anteriores.

\section{BIBLIOGRAFÍA}

ALFARO, C. (2004): Sylloge Nummorum Graecorum, España, Volumen I, Hispania, Ciudades Feno-púnicas. Parte 2: Acuñaciones cartaginesas en Iberia y emisiones ciudadanas (continuación). Madrid.

- (1997): «Las emisiones fenopúnicas», en Alfaro, C., et alii, Historia monetaria de Hispania Antigua. Madrid, 1997, pp. 50-115.

CAMPO, M. (1993): «Las monedas de Ebussus», Trabajos del Museo arqueológico de Ibiza y Formentera, 31, pp. 141-171.

- (1976): Las monedas de Ebussus. Barcelona.

CAMPO, M. y MORA, B. (1995): Las monedas de Malaka. Madrid.

CHAVES, F. (1997): «Amonedación de las cecas latinas de la Hispania Ulterior», en Alfaro, C., et alii, Historia monetaria de Hispania Antigua. Madrid, pp. 233-317.

- (1979a): Las monedas Hispano - Romanas de Carteia. Barcelona.

- (1979b): «Las cecas hispanorromanas de Ebora, lulia Traducta y Colonia Romula», Numisma, 156-161, pp. 9-91.

CHAVES, F. y GARCÍA VARGAS, E. (1991): «Reflexiones en torno al área comercial de Gades: Un estudio numismático y económico", en Alimenta. Estudios en homenaje al Dr. Michel Ponsich [Gerión, Anejos Gerión 3], Madrid, pp. 139-168.

GARCÍA-BELLIDO, M. ${ }^{a}$ P. (1993): «Las Cecas Libiofenicias», en Numismática Hispano-Púnica. Estado actual de la investigación. VII Jornadas de Arqueología Fenicio-Púnica (Ibiza, 1992). Ibiza, pp. 97-146.

- (1990): «Iconografía fenicio-púnica en moneda romano-republicana de la Bética», Zephyrus, 43 , pp. 371-383.

MORA, B. (1993): «Las cecas de Malaca, Sexs, Abdera y las acuñaciones púnicas de la Ulterior Baetica», en Numismática Hispano Púnica. Estado Actual de la Investigación. VII Jornadas de Arqueología Fenicio-Púnica (Ibiza, 1992). Ibiza, pp. 63-95.

RIPOLLÉS, P. P. (2005): Monedas hispánicas de la Bibliothèque National de France. Madrid.

- (1997): «Las acuñaciones cívicas romanas», en Alfaro, C., et alii, Historia monetaria de Hispania Antigua. Madrid, pp. 335-395.

ROLDÁN, L.; BENDALA, M.; BLÁNQUEZ, J.; MARTÍNEZ, S. y BERNAL, D. (2003): Carteia II. Madrid. 
